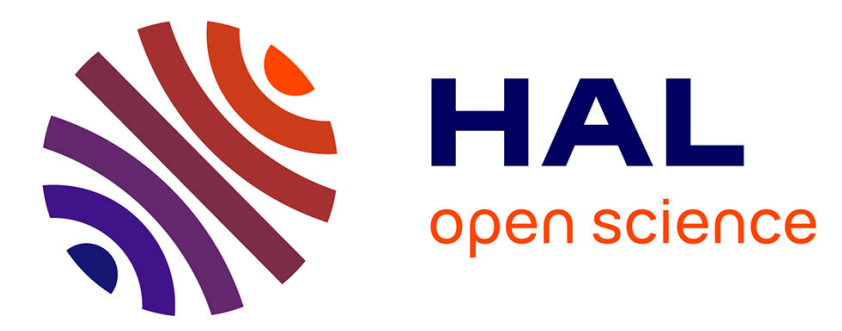

\title{
Potential and limitations of microanalysis SEM techniques to characterize borides in brazed Ni-based superalloys
}

José Ruiz-Vargas, Nathalie Siredey-Schwaller, Pierre Noyrez, Sandrine Mathieu, P. Bocher, Nathalie Gey

\section{To cite this version:}

José Ruiz-Vargas, Nathalie Siredey-Schwaller, Pierre Noyrez, Sandrine Mathieu, P. Bocher, et al.. Potential and limitations of microanalysis SEM techniques to characterize borides in brazed Ni-based superalloys. Materials Characterization, 2014, 94, pp.46-57. 10.1016/j.matchar.2014.04.009 . hal01513630

\section{HAL Id: hal-01513630 \\ https://hal.univ-lorraine.fr/hal-01513630}

Submitted on 13 Dec 2019

HAL is a multi-disciplinary open access archive for the deposit and dissemination of scientific research documents, whether they are published or not. The documents may come from teaching and research institutions in France or abroad, or from public or private research centers.
L'archive ouverte pluridisciplinaire HAL, est destinée au dépôt et à la diffusion de documents scientifiques de niveau recherche, publiés ou non, émanant des établissements d'enseignement et de recherche français ou étrangers, des laboratoires publics ou privés. 


\title{
Potential and limitations of microanalysis SEM techniques to characterize borides in brazed Ni-based superalloys
}

\author{
J. Ruiz-Vargas ${ }^{a, b}$, N. Siredey-Schwaller ${ }^{a, c}$, P. Noyrez ${ }^{d}$, S. Mathieu ${ }^{e}$, P. Bocher ${ }^{b}$, N. Gey ${ }^{a, c, *}$ \\ ${ }^{a}$ Laboratoire d'Étude des Microstructures et de Mécanique des Matériaux (LEM3), UMR CNRS 7239, Université de Lorraine, 57045 Metz, France \\ bÉcole de Technologie Supérieure (ÉTS), Université du Québec, Montréal, Canada \\ ${ }^{\mathrm{C}}$ Laboratory of Excellence on Design of Alloy Metals for low-mAss Structures (DAMAS), Université de Lorraine, France \\ ${ }^{\mathrm{d} C e n t r e ~ d e ~ C o m p e ́ t e n c e s ~ e n ~ M i c r o s c o p i e s ~ E l e c t r o n i q u e s ~ e t ~ M i c r o s o n d e s ~(C C-M E M), ~ I n s t i t u t ~ J e a n ~ L a m o u r ~(I J L), ~ U M R ~ C N R S ~ 7198, ~}$ \\ Université de Lorraine, 54011 Nancy, France \\ éService Commun de Microscopies Electroniques et de Microanalyses X (SCMEM), Université de Lorraine, 54506 Vandoeuvre les Nancy, France
}

\section{A R T I C L E D A T A}

\section{Keywords:}

Ni-based superalloys

Boron quantitation

EDS

SEM-WDS

EPMA

EBSD

\begin{abstract}
A B S T R A C T
Brazed Ni-based superalloys containing complex phases of different Boron contents remain difficult to characterize at the micrometer scale. Indeed Boron is a light element difficult to measure precisely. The state-of-the-art microanalysis systems have been tested on a single crystal MC2 based metal brazed with BNi-2 alloy to identify boride precipitates. Effort has been made to evaluate the accuracy in Boron quantitation. Energy-dispersive and wavelength-dispersive X-ray spectroscopy attached to a Scanning Electron Microscope have first been used to determine the elemental composition of Boron-free phases, and then applied to various types of borides. Results have been compared to the ones obtained using a dedicated electron probe microanalysis, considered here as the reference technique. The most accurate method to quantify Boron using EDS is definitely by composition difference. A precision of 5 at.\% could be achieved with optimized data acquisition and post-processing schemes. Attempts that aimed at directly quantifying Boron with various standards using EDS or coupled EDS/WDS gave less accurate results. Ultimately, Electron Backscatter Diffraction combined with localized EDS analysis has proved invaluable in conclusively identifying micrometer sized boride precipitates; thus further improving the characterization of brazed Ni-based superalloys.
\end{abstract}

\section{Introduction}

Complex Ni-based superalloy components used in aeronautic applications are often joined together by isothermal brazing [1]. Chemically complex microstructures result from such a process. The base metal is usually a multi-element alloy that often contains more than seven elements. During isothermal solidification its constituting elements interact with the diffusing elements of the filler metal, Boron in particular. Dissolution of the base metal occurs at the initial stages of the

\footnotetext{
* Corresponding author at: LEM3 Bât.B ISGMP, Université de Lorraine, Ile du Saulcy, 57045 Metz Cedex 01, France. Tel.: +33 387315385 ; fax: + 33387315377 .

E-mail addresses: joseruizvargas@gmail.com (J. Ruiz-Vargas), nathalie.siredey@univ-lorraine.fr (N. Siredey-Schwaller), pierre.noyrez@ijl.nancy-universite.fr (P. Noyrez), Philippe.Bocher@etsmtl.ca (P. Bocher), nathalie.gey@univ-lorraine.fr (N. Gey).
} 
brazing process [2]. Should isothermal solidification not be completed then bulky borides are expected inside the brazed joint. On the other hand, the diffusing elements are prone to precipitate in the base metal.

Very limited microstructural studies including accurate phase identifications are available in the literature for brazed Ni-based superalloys [1,3-6]. A few authors [6] have used laser abrasion coupled with inductively coupled plasma mass spectrometry that is a very specialized technique. Transmission electron microscopy and X-ray diffraction [3] have also been employed to determine the nature of the borides. Unfortunately, tedious sample preparation is required and the precise location of the phases inside the brazed area is not very well known. Electron Backscatter Diffraction (EBSD) has also been applied to identify orientation variations over the solidification front [1].

Electron probe microanalysis (EPMA) using Wavelength Dispersive Spectroscopy is also an excellent technique but is time consuming and requires expensive equipment. The usual way to detect the presence of Boron remains X-ray microanalysis like Energy Dispersive Spectroscopy (EDS) or sometimes Wavelength Dispersive Spectroscopy (WDS) attached to a Scanning Electron Microscope (SEM). Unfortunately both techniques exhibit severe limitations for the quantitation of light elements. As a result, published papers dealing with the quantitation of Boron and the identification of phases located within the brazed joint are very often more than approximate. Precision on the Boron content is seldom indicated and very limited information is provided with regard to the measurement conditions. Experimental results are thus often compared with thermodynamic calculations to confirm the nature of the borides [7-9].

Quantitative analysis of Boron is of major importance since Boron is considered as the most important diffusing element that drives the solidification process. As a result, the uncertainty on Boron values leads to a true lack of understanding of the isothermal brazing process of Ni-based superalloys. Recent progresses in X-ray microanalysis systems should help improve the quality of the analyses in such challenging situations. Indeed, Silicon Drift Detectors in EDS systems allow higher counting rates, improved peak-to-background ratios; thus lead to more precise measurements $[10,11]$. Spectral resolution has also improved. Peak deconvolution processes have become more accurate thanks to better software mathematical treatments of the acquired datasets. In parallel, latest progresses in the EBSD technique have made it a powerful tool for phase identification.

This study aims (1) at evaluating the precision of the state-of-the-art microanalysis systems attached to a SEM (EDS, WDS, EBSD) for the determination of the elemental composition and crystal structure of phases present in brazed Ni-based superalloys, and (2) at deducing the best technique or combination of techniques for the accurate identification of borides.

For that purpose the different phases formed in a brazed MC2 superalloy have been investigated thoroughly: EDS and WDS attached to a SEM were tested on Boron-free phases then applied to different Boron-rich phases. SEM-EDS and SEM-WDS results were compared to the ones obtained using electron probe microanalysis (EPMA), considered here as the reference technique. Various parameters impacting the quality of the quantitation processes have been recalled and an optimized methodology proposed to decrease discrepancies, especially when measuring Boron. Finally it was shown that EBSD coupled with EDS can be useful for further phase identification, taking the crystal structure into account. Results from this study may help researchers set the best measurement conditions for their microanalysis system in order to improve the characterization of brazed Ni-based superalloys.

\section{Experimental}

\subsection{Ni-based Superalloy and Brazing Conditions}

A Ni-based single crystal superalloy of MC2 type containing seven alloying elements (Al-Ti-Cr-Co-Mo-Ta-W) was investigated. Its nominal composition range is indicated in Table 1 according to [12]. Additional chemical analysis by EPMA and EDS/WDS was performed on the as-received single crystal. The result indicated in Table 1 confirms that its chemical composition is consistent with the nominal composition of MC2 type Ni-based superalloy (considering a precision of about 0.5 at.\%). Prior to brazing, a $5 \mu \mathrm{m}$ thick $\mathrm{Ni}$ coating was electrodeposited at its surface. Filler metal was a BNi-2 paste with composition (expressed as at.\%): Ni, 6.6Cr, 2.65Fe, 7.9Si, and 13.7B. The system was isothermally brazed at $1323 \mathrm{~K}\left(1050{ }^{\circ} \mathrm{C}\right)$ for $30 \mathrm{~min}$, then slowly cooled down to $811 \mathrm{~K}\left(538^{\circ} \mathrm{C}\right)$. A sample was cut perpendicular to the brazed interface and mechanically polished with a $0.25 \mu \mathrm{m}$ diamond suspension.

The complex microstructure of the brazed assembly (base metal including the diffusion zone and the filler zone) is visible in Figs. 1 and 2. MC2 base metal is classically characterized by $\gamma / \gamma^{\prime}$ precipitates. Qualitative microstructural and chemical analyses of the brazed joint have shown that at the interface between the base metal and the brazed zone, two kinds of borides can be found: needle-shaped and bulky ones (Fig. 2b). A few borides extend over the base metal within the $\gamma$-channels, up to a distance of $50 \mu \mathrm{m}$ from the interface. Those borides are usually too small for any reliable quantitative X-ray chemical analysis.

In the brazed joint, five bulky phases can be found: (1) $\gamma$ $\mathrm{Ni}$ rich isothermal solidification front (free of $\gamma^{\prime}$ precipitates) and without Boron (amount below detection limit); (2) Si-rich phase - most likely $\alpha-\mathrm{Ni}$, including $\mathrm{Ni}_{3} \mathrm{Si}$ precipitates (not resolved in Fig. 2); (3) very few $\mathrm{Cr}$, Mo-rich borides (B-1 in Fig. 2); and finally two types of Ni-rich borides (B-2 and B-3 in Fig. 2a; B-2 containing Ta \& Ti at significant level).

This Ni-coated MC2 superalloy brazed with BNi-2 alloy is especially challenging with regard to quantitative analyses. Up to 11 elements are involved: Ni (matrix element), $\mathrm{Al}, \mathrm{Cr}, \mathrm{Ti}$, Co, Mo, Ta, W (already present in the base metal), and B, Fe and Si (present in the filler). A typical EDS spectrum (Fig. 3) highlights the main encountered difficulties. Many overlapping peaks can be noted:

- W-L $\alpha$ and Ta-L $\alpha$ peaks lie near the Ni-K $\beta$ peak,

- Si-K $\alpha$ peak overlaps $\mathrm{W}-\mathrm{M} \alpha$ and Ta-M $\alpha$ peaks,

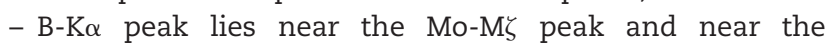
contamination $\mathrm{C}-\mathrm{K} \alpha$ peak.

The presence of Boron, as a light element, increases the difficulties for an accurate quantitative elemental analysis, but its exact determination is of great importance to 
Table 1 - Elemental at.\% composition in Ni-based homogenized MC2 alloy; composition range for MC2 (1.1) confirmed by EPMA, EDS/WDS (1.2-3) and finally EDS results with two quantitation methods (1.4-5). FS parameter prior to normalization is also indicated. The amounts of Ta and W were determined from L $\alpha$ peaks on EPMA and EDS/WDS systems and from M $\alpha$ peaks on EDS system.

\begin{tabular}{|c|c|c|c|c|c|c|c|c|c|c|c|}
\hline at.\% & $\mathrm{Al}$ & $\mathrm{Ti}$ & $\mathrm{Cr}$ & Co & $\mathrm{Ni}$ & Mo & $\mathrm{Ta}$ & W & $\mathrm{Si}$ & B & FS wt.\% \\
\hline $\begin{array}{l}\text { Recommended composition } \\
\text { range for MC2 [12] }\end{array}$ & $10.79 / 11.42$ & $1.64 / 2.02$ & $8.97 / 9.55$ & $4.94 / 5.55$ & $65.28 / 68.05$ & $1.14 / 1.39$ & $1.94 / 2.08$ & $2.53 / 2.71$ & 0 & 0 & \\
\hline EPMA & 11.3 & 2.0 & 9.1 & 5.5 & 66.8 & 1.3 & 2.0 & 2.1 & n.d. & n.d. & $98.4 / 100.6$ \\
\hline $\begin{array}{l}\text { EDS/WDS (WDS is for Ti, Ta, W, } \\
\text { and Mo peaks) }\end{array}$ & 10.8 & 1.8 & 9.3 & 5.5 & 67 & 1.3 & 1.7 & 2.5 & n.d. & n.d. & $99 / 100.5$ \\
\hline $\begin{array}{l}\text { EDS with the } \phi(\rho z) \text { method } \\
10^{6} \text { count standards }\end{array}$ & 10.9 & 1.9 & 9.3 & 5.3 & 66.7 & 1.1 & 1.6 & 2.8 & 0.4 & n.d. & 101.4 \\
\hline EDS system with P/B ZAF method & 10.5 & 2.0 & 8.7 & 5.3 & 68.5 & 1.1 & 1.4 & 2.4 & 0 & n.d. & 92.9 \\
\hline
\end{tabular}

understand the brazing process since the diffusion of Boron controls the progress of the solidification front.

\subsection{Methods for Elemental Quantitation and Phase Identification}

Three X-ray microanalysis techniques were used for the acquisition of elemental data: (1) EPMA considered in this study as the reference technique; (2) EDS with and without standards and (3) coupled WDS/EDS on SEM. Finally, EBSD coupled to EDS was also tested since it can offer additional phase identification, taking crystallographic features into account.

The quantitation process using sample standards was carried out using advanced matrix correction methods, as described by Pouchou [13]; the general principle was briefly summarized below.

For each element present in the analyzed sample, intensity of the characteristic X-ray emission line was measured and

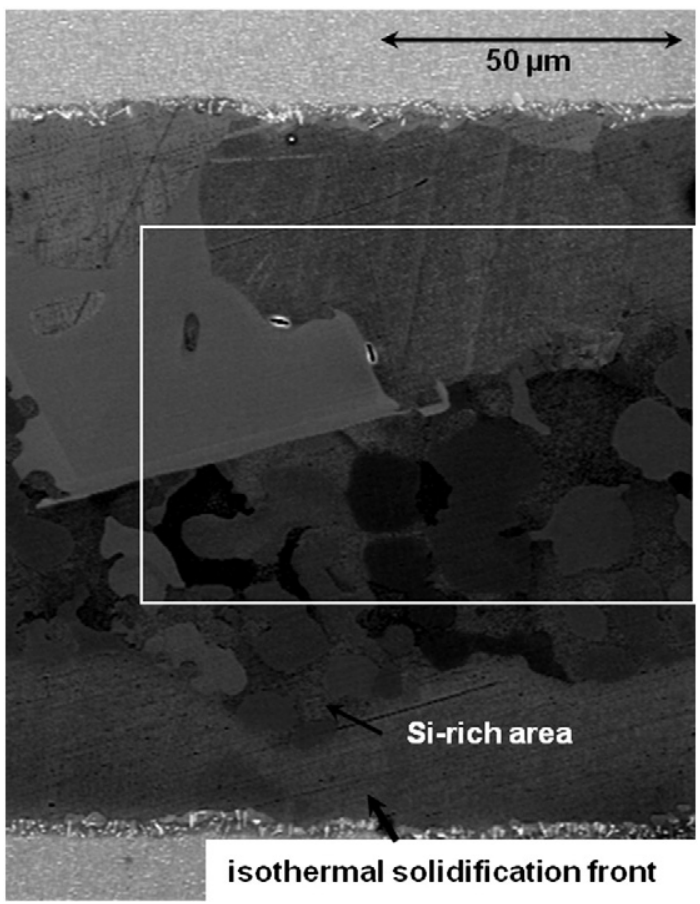

Fig. 1 - SEM-BSE micrograph of the brazing area. The white box marks the area in Fig. $2 a$. compared to the one obtained from a suitable standard of known composition that was analyzed the same way. Their ratio is called k-ratio; the latter was defined more precisely in Eq. (1). Post-processing calculations have to be run, in order to apply matrix corrections such as atomic number $\mathrm{Z}$, absorption effects A (involving Mass Absorption Coefficients M.A.C.s) and also secondary fluorescence $\mathrm{F}$.

Elemental weight fraction $C_{i}$ for any given element ' $i$ ' is then obtained from the corresponding $\mathrm{k}_{\mathrm{i}}$-ratio according to Eq. (2). Since the correction coefficient (called ZAF) depends on

a)

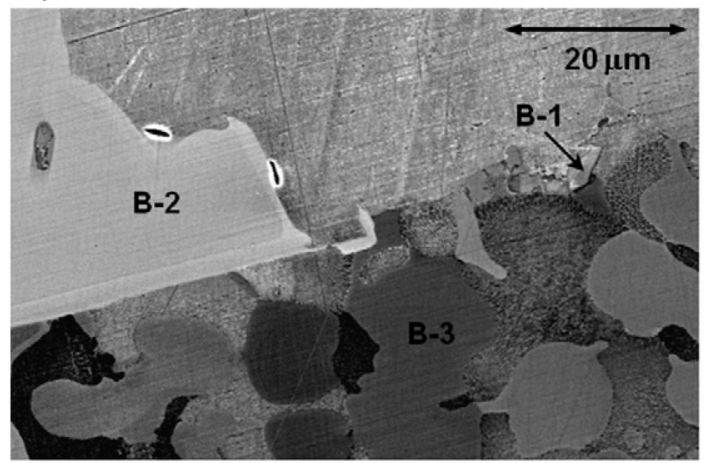

b)

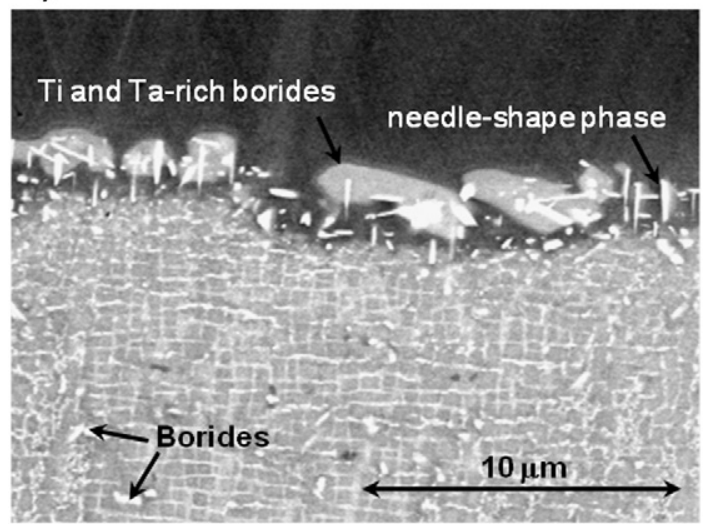

Fig. 2 - Detailed view of Fig. 1. (a) Three different kinds of borides are observed inside the brazing zone: $\mathrm{Cr}$-rich ones (labeled 'B-1'), borides containing Ni, Ti \& Ta (labeled 'B-2') and Ni-rich ones (labeled 'B-3'). (b) Area around the interface between base metal (bottom) and brazing area (top). Various types of borides are also observed here. 


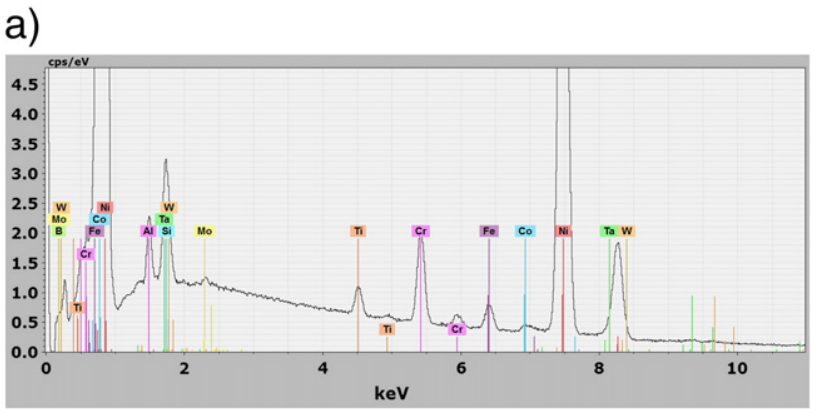

b)

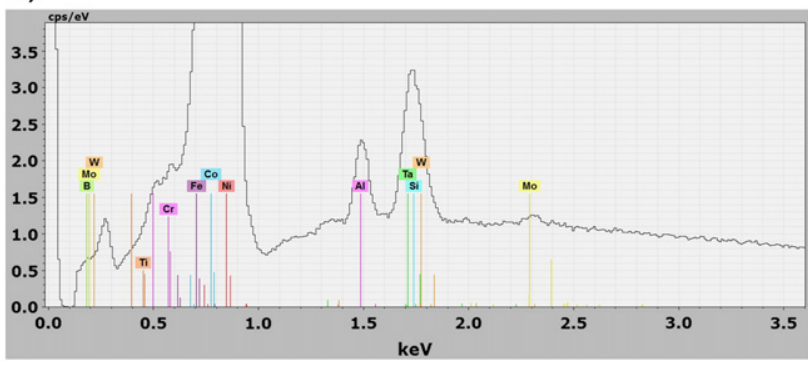

Fig. 3 - EDS spectrum acquired at an accelerating voltage of $15 \mathrm{kV}$ of a Ni, Ti \& Ta-containing boride (of 'B-2' type). (a) Spectrum up to $10 \mathrm{kV}$. (b) Detailed view in the low energy range.

the concentration of all elements present in the sample, the final solution is found using a converging iterative process.

$\mathrm{k}=\frac{\mathrm{I}_{\text {emission-line_sample }}-\mathrm{I}_{\text {background_sample }}}{\mathrm{I}_{\text {emission-line_standard }}-\mathrm{I}_{\text {background_standard }}}$

$\mathrm{C}_{\mathrm{i}(\mathrm{wt} . \%)}=\mathrm{k}_{\mathrm{i}}\left[\mathrm{ZAF}\left(\mathrm{C}_{1}, \ldots, \mathrm{C}_{i}, \ldots, \mathrm{C}_{11}\right)\right]$

The sum of the elemental weight fractions obtained after matrix correction is called here FS (see Eq. (3)).

$\mathrm{FS}=\sum_{\mathrm{i}} \mathrm{C}_{\mathrm{i}}$

If no element is missing, FS should ideally equal $100 \%$. But often small discrepancies still subsist due to quantitation errors (over or below 100\%). The sum of the elemental weight fractions is usually normalized to $100 \%$.

If one element is missing, then FS is no longer equal to $100 \%$; the discrepancy links with the weight fraction of the missing element (as well as to errors in the whole quantitation). As a consequence, the weight fraction of the missing element can then be evaluated from the composition difference and included in the iterative process. This requires all other elements to be quantified with a high accuracy.

As detailed later, different standard samples (B, BN, NiB) have been tested for Boron quantitation by the different techniques: EDS, WDS and EPMA. Pure Boron offers high count signal. However, B-K $\alpha$ peak shape and maximum in energy differ from those of chemically complex borides. Thus this standard was mainly used when the total peak area is analyzed in the quantitation, as it is the case by EPMA. BN standard is the classical standard provided in MAC 7478 package. Of course, the $\mathrm{B}-\mathrm{K} \alpha$ peak shape still differs from those of chemically complex borides. Also, it cannot be used by EPMA due to 2nd order N-K $\alpha$ peak overlapping. Finally, NiB was assumed to be the closest in peak shape to our material. It was mainly used for quantitation by SEM-WDS. However very low count signal is obtained due to high absorption by $\mathrm{Ni}$.

\subsubsection{Electron Probe Microanalysis}

Results obtained from EPMA were used as reference datasets for the quantitative elemental analyses [14]. This technique is known to offer a very high spectral resolution. Each characteristic emission line is selected based on its wavelength thanks to the accurate positioning of an analyzing crystal according to the Bragg diffraction law. The accelerating voltage of the electron beam can be chosen for each element in order to improve the signal/background ratio. Usually, several elements (typically 3) can be measured simultaneously. For quantitative analysis, each and every k-ratio is measured with regard to an appropriate standard of known composition. Unfortunately, analyses are rather time-consuming. Indeed, even when using several analyzing crystals simultaneously, peak and background intensities usually have to be measured sequentially. Special attention has to be paid to multi-order peaks ( $n=2,3, \ldots$ in the Bragg law) and to the accurate positioning of the sample on the Rowland's circle.

Our measurements were performed using a JEOL FEG JXA-8530F microprobe. Analytical conditions (beam current $\&$ accelerating voltage) were chosen in order to maximize the intensity of the characteristic emission lines. A beam current of $300 \mathrm{nA}$ and an accelerating voltage of $10 \mathrm{kV}$ were chosen for the analysis of $\mathrm{B}, \mathrm{Al}, \mathrm{Si}$ and $\mathrm{Mo}$, whereas for the other elements a beam current of $23 \mathrm{nA}$ and an accelerating voltage of $20 \mathrm{kV}$ were used. It might be worth mentioning that another series of analyses was also successfully carried out using a beam current of $50 \mathrm{nA}$ and an accelerating voltage of $15 \mathrm{kV}$ for all elements for B-1 boride. Quantitative results were obtained from the StrataGem v 4.6 software (from SAMx); the latter was able to cope with k-ratios obtained at different accelerating voltages.Matrix correction scheme was derived from the XXP model proposed by Pouchou \& Pichoir decribed in [13].

Thanks to the high spectral resolution of the analyzing crystals attached to the EPMA, all emission lines (except B-K $\alpha$ and Mo-M $\zeta$ ) could be separated, thus analyzed without significant interferences from the other elements. When multi-order reflections occurred, standard energy filtering techniques (using narrow PHA windowing) enabled their elimination. Quantitation was carried out using pure metals and/or stoichiometric oxides $\left(\mathrm{Al}_{2} \mathrm{O}_{3}\right.$ for instance). Boron was quantified using a pure $\mathrm{B}$ standard and with the LDE2H analyzer. Since the $\mathrm{B}-\mathrm{K} \alpha$ peak is sensitive to its chemical environment, the total area under the peak rather than its maximum intensity was used to measure the Boron k-ratio. For that purpose, wavelength scans (comprising the overall $\mathrm{B}-\mathrm{K} \alpha$ peak) were recorded over a region centered on the $\mathrm{B}-\mathrm{K} \alpha$ peak. Boride phases containing fairly large amount of Mo (i.e., B-1 type borides) requested an additional mathematical treatment. In this case, the cumbersome overlapping Mo-M $\zeta$ contribution was numerically subtracted from the B-K $\alpha$ peak using a pre-recorded Mo-M $\zeta$ spectrum of pure Mo. Carbon contamination was not taken into account. The high vacuum quality of the FEG microprobe significantly limits the 
contamination. Moreover, under the operating conditions, the signal absorption from the carbon layer is very small so that it can be neglected.

\subsubsection{Energy Dispersive Spectrometry (EDS)}

Energy Dispersive Spectrometry analysis was carried out with the Quantax Bruker system attached to the FEG SEM ZEISS SUPRA 40. A $10 \mathrm{~mm}^{2}$ SDD detector was used. Spectral resolution of the detector was such that full-width-at-half-maximum value was $131 \mathrm{eV}$ for $\mathrm{Mn}-\mathrm{K} \alpha$ and $80 \mathrm{eV}$ for Si-K $\alpha$. Operating conditions for the primary electron beam were $4 \mathrm{nA}$ and $15 \mathrm{kV}$. For each analyzed point, a spectrum of at least $10^{6}$ counts was recorded.

Elemental compositions were calculated using k-ratios, so standard spectra were also recorded. Datasets were postprocessed with the ESPRIT-Bruker software. Special precautions were taken when analyzing $\mathrm{Ta}, \mathrm{W}$ and $\mathrm{Si}$. The $\mathrm{M} \alpha$ rather than the $\mathrm{L} \alpha$ emission lines were used to quantify Ta and $\mathrm{W}$. Indeed, the $\mathrm{Si}-\mathrm{K} \alpha, \mathrm{Ta}-\mathrm{M} \alpha$, and $\mathrm{W}-\mathrm{M} \alpha$ peaks overlapped with similar intensities. In such a case, the post-processing software performed better when separating the different peaks. On the opposite, Ta-L $\alpha$ and $\mathrm{W}-\mathrm{L} \alpha$ peaks overlapped with the Ni-K $\beta$ peak with significantly different intensities.

It was found that the most accurate quantitation of Boron was obtained by composition difference as proven later. However, this required precise quantitation of all the other elements. This has nowadays become possible with the state-of-the-art EDS systems, as demonstrated later on Boron-free phases.

\subsubsection{Coupling Wavelength and Energy Dispersive Spectrometry on SEM}

Measurements were made on the JEOL FEG J7600F equipped with an Oxford INCA system. Its SDD detector had a surface of $20 \mathrm{~mm}^{2}$. This higher surface allowed more signal to be obtained for a given beam current intensity. The working principle of the SEM-WDS system is close to that of the EPMA and the spectral resolution is greatly improved in comparison to EDS. WDS was used to quantify Boron and EDS for the other elements. This shortened the analysis time while improving spectral resolution for Boron. Regarding beam current, a compromise had to be found: not too high to avoid EDS detector saturation and limit carbon contamination but high enough to get sufficient signal for WDS measurements. The acquisition time was set to $300 \mathrm{~s}$ per point. Operating conditions were a beam current of $29 \mathrm{nA}$ and an accelerating voltage of $15 \mathrm{kV}$. For the measurement of Boron in WDS the LSM 200 spectrometer was used. k-Ratios of the different elements were measured from various standards. Here the k-ratio for Boron was obtained from the maximum peak intensities measured from sample and standard. A NiB standard was chosen for Boron measurements. Its composition was as close as possible from the analyzed borides and it was anticipated that this would limit the effects due to the chemical environment.

\subsection{Electron Backscatter Diffraction Analysis}

EBSD is a well-known SEM microanalysis technique that is used to measure the local orientation of known crystalline phases present in bulk materials [15]. The orientation of individual grains is obtained based on reliable indexing of the Electron Backscatter Diffraction pattern that is recorded using an ultra-sensitive camera. Data is frequently acquired in mapping mode to determine the spatial orientation distribution in relation to the microstructure of the material.

More recently, it was demonstrated that EBSD could also be a powerful tool for identifying and differentiating different phases $[15,16]$. For such an application, it is of interest to combine EBSD and EDS data; the richness of information provided by both techniques can be essential to discriminating crystal structures and determining their orientation simultaneously. Commercial solutions with fully integrated EBSD/EDS systems are now available; they usually offer different routines to combine EBSD and EDS data for microanalysis. EDS provides qualitative information about the elemental composition to select a list of possible candidate phases from a relevant database. This list is used in a second step as an input to the EBSD indexing procedure.

However, the coupled EBSD/EDS approach is limited by two aspects. First, both techniques have large differences in depth resolution: in the range of micrometer for EDS and a few tens of nanometers for EBSD. Secondly optimum data acquisition for EDS and EBSD analysis is also often very different in terms of counting time (a few seconds for EDS and few milliseconds for EBSD) and sample positioning (zero tilt for EDS and $70^{\circ}$ tilt for EBSD). All these aspects make the fully automated routines less efficient for identifying the phases and deducing their orientation, especially on sub-micrometer phases containing light elements. As a result, semi-automated routines are often recommended for the identification of tricky phases.

In this study, the integrated EBSD/EDS Quantax CrystAlign system (Bruker) attached to the SEM FEG ZEISS SUPRA 40 was used. The crystal structure of different borides was identified in a semi-automated way, with the advanced interactive phase identification mode available in the software tool box.

At a given beam position, a high quality EDS spectrum was acquired and qualitatively analyzed to preselect a list of phases from the ICSD (Inorganic Crystal Structure Data) database. The list could result in more than 300 candidates. At the same beam position, a high resolution EBSD pattern was acquired and 12 diffraction bands detected and further used to index the pattern with all the preselected phases. Solutions were ranked based on a best fit index over the 12 detected bands between the experimental and simulated diffraction patterns. For complicated crystal structures, it is recommended to check visually the quality of the fits over a larger number of diffraction bands than the twelve automatically detected ones. Especially low diffraction intensity bands are key features for reliable indexing.

Finally an EBSD map was acquired with the different identified phases (the step size of the map was $0.2 \mu \mathrm{m}$ ). The EDS signal was simultaneously acquired to get a qualitative mapping of the elemental distribution.

\section{EDS Accuracy for the Multi-element Ni-based Matrix (Boron-free)}

At first, the Boron-free regions of the brazed MC2 superalloy were analyzed to evaluate the ability of X-ray microanalysis techniques to provide reliable compositions (even if the case of strongly overlapping peaks is shown in Fig. 3). Our final goal was to determine how accurately Boron can be quantified by difference with EDS (once reliable quantitation of all other elements is demonstrated). 


\subsection{Microanalysis Results on Boron-free Regions}

Table 1 (line 4 to 5) shows the quantitative EDS results obtained on a region of the MC2 base metal, far away from the brazed interface (to be compared to the recommended composition range for MC2, confirmed by further EPMA and WDS/EDS analyses on the as-received material). Two correction methods were applied: the $\phi(\rho z)$ method as available in the EDS software with $10^{6}$ count standard spectra and the classical P/B ZAF method without any standards (in that case, peak intensity is compared to background intensity). We have not taken the carbon contamination into account for EDS quantitation. It can be assumed that it alters very little the heavy-element quantitation, mainly present in MC2.

As expected, the $\phi(\rho z)$ matrix correction method was the only method able to reach FS values close to $100 \%$ (Table 1 ). Using the P/B ZAF correction method, the sum was far from $100 \%$. This method is definitely not adapted to the quantitation of Boron by difference, which is in agreement with the already known recommendations for reliable EDS analyses.

Comparing the EDS results with the nominal composition of the base metal shows that a precision of about 0.5 at.\% can be obtained for each element with the $\phi(\rho z)$ method. One can note that the quantitation was performed supposing the presence of $\mathrm{Si}$ even if MC2 base metal contains no $\mathrm{Si}$. Si is only present in the filler metal and consequently some areas of the brazed joint contain this diffusing element. It was important to check that the tested method was able to measure the Si amount. Indeed, $\mathrm{Si}$ is especially difficult to measure in this alloy since the post-processing software has to separate strongly overlapping peaks (between $\mathrm{Ta}, \mathrm{W}$ and $\mathrm{Si}$ ). The result shows that $\mathrm{Si}$ level was overestimated with an error of only about 0.5 at.\%. The result is even lower when considering the sum of the three overlapping elements.

Similar EDS analyses were repeated over the homogenized base metal. The quantitation results were always within the error range observed in Table 1. FS parameter was always close to $100 \%$ with a deviation of $1 \mathrm{wt} . \%$ (at best). Thus if Boron would be quantified by difference, about 1 wt.\% would be obtained. This corresponds to an error in Boron quantitation of about 5 at.\% in MC2 alloy.

Table 2 gives similar EDS results on the isothermal solidification region that is Boron-free, according to the EPMA. Chemical segregations can be found in this phase and may explain the observed variations for points 1, 2 and 3. However, Table 2 confirms that no Boron was detected by optimized EDS analysis. FS factor prior to normalization was $101.5 \%$.

\subsection{Discussion}

Our analyses demonstrate that the state-of-the-art EDS systems can quantify the multi-elements of $\mathrm{Ni}$ based superalloys with a precision of about 0.5 at.\% for each element (Table 1). To reach this precision level, classical recommendations for high resolution EDS must be applied. The best spectral resolution mode of the detector should be used and a spectrum comprising at least $10^{6}$ counts was recorded. The $\phi(\rho z)$ correction method must be applied. With this number of counts, a good precision from X-ray statistics is obtained in reasonable time, depending on the electronic intensity. Relative precision on k-ratio is then $0.2 \%$.

One has to take care of the current stability of the primary electron beam (FEG-SEM is recommended as it offers higher beam stability - we checked before and after analyses that the current was identical).

It is further recommended to select peaks of the same order of magnitude to correctly determine k-ratios on overlapping peaks. For example, in the BNi-2 brazed MC2 superalloys, Si, Ta and W elements were satisfactorily quantified by deconvolution of the three peaks of similar intensities. This shows the performance of nowadays post-processing software to separate overlapping peaks.

Consequently the Boron content can reasonably be determined by difference. In most of the cases, no Boron was detected in Boron free phases using $\phi(\rho z)$ method with $10^{6}$ count for the standards. However, according to variation in FS parameter from one measurement to the next, an error in Boron quantitation of about 5 at.\% in MC2 alloy must be considered. Of course this requires an accurate quantitation of all other elements. The method by difference applied to light element quantitation also allows minimizing in EDS the effect of carbon contamination. It is worth mentioning that Boron can be evaluated by difference only if no additional element is missing in the quantitation. Special care is required if other elements, like $\mathrm{H}$ or Li not detectable by EDS could be present. Fortunately, they are not present in Ni-based superalloys. Once these precautions have been taken, it becomes possible to quantify Boron by difference with an accuracy of less than 5 at.\%.

\section{Accuracy of the Elemental Analysis of Borides}

Three types of bulky borides were selected for those additional EDS analyses: B-1: Cr-Mo-W rich, B-2: Ni-Ta-Ti rich, and B-3: Ni-rich (Fig. 2a). Different methods were applied to quantify the Boron content and the EDS results were compared to the results obtained using the EPMA. To optimize the analysis, the specific issues linked to the quantitation of Boron are first described below.

\subsection{Special Care Linked to the Quantitation of Boron}

The direct quantitation of Boron in Ni-based superalloys is tricky with EDS and even with WDS systems for the reasons detailed below.

Table 2-Elemental at.\% composition at various locations inside the solidification front using the microprobe and EDS system ( $\phi(\rho z)$ method and $10^{6}$ count standards were applied).

\begin{tabular}{lccccccccccc}
\multicolumn{1}{c}{ at.\% } & $\mathrm{Al}$ & $\mathrm{Ti}$ & $\mathrm{Cr}$ & $\mathrm{Co}$ & $\mathrm{Ni}$ & $\mathrm{Mo}$ & $\mathrm{Ta}$ & $\mathrm{W}$ & $\mathrm{Si}$ & $\mathrm{Fe}$ & $\mathrm{B}$ \\
\hline Microprobe point 1 & 1.5 & 0.1 & 5.3 & 0.7 & 82.4 & 0.2 & 0.2 & 0.4 & 6.9 & 2.4 & 0 (B standard) \\
EDS point 2 & 1.3 & 0.2 & 5.5 & 0.6 & 82.8 & 0.1 & 0 & 0.6 & 6.4 & 2.5 & 0 (difference) \\
EDS point 3 & 1.2 & 0.1 & 6.5 & 0.4 & 81.7 & 0.1 & 0 & 0.4 & 6.7 & 2.9 & 0 (difference) \\
\hline
\end{tabular}




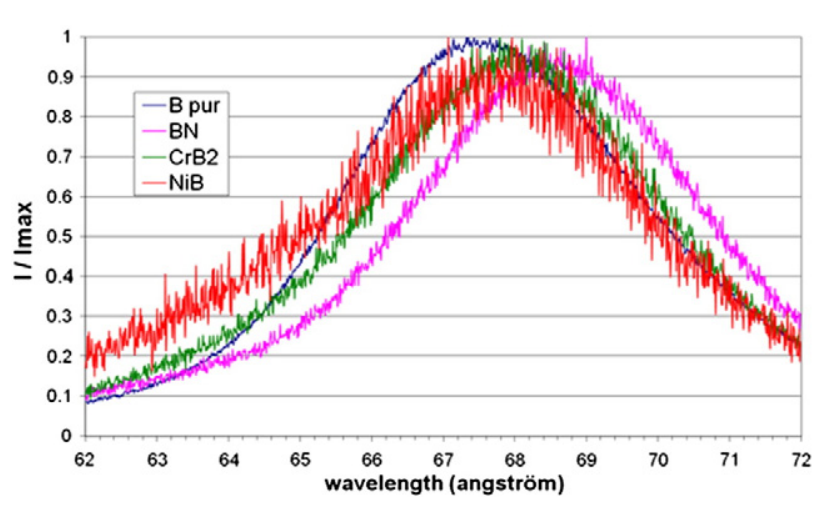

Fig. 4 - Normalized spectral scans of various Boron-containing standard samples recorded with a SEM-WDS attached to the JEOL J7600F ( $\mathrm{i}=29 \mathrm{nA}, \mathrm{V}=15 \mathrm{kV}$ ) fitted with a LSM 200 analyzing crystal. A few spectra are noisy due to the low Boron level and the high Boron absorption in Ni. It is worth mentioning the spectral shift of the $\mathrm{B}-\mathrm{K} \alpha$ peak caused by the chemical environment.

First, the B-K $\alpha$ peak has a low intensity due to its high absorption in the Ni matrix. In addition, its peak position in the spectrum is located in the low energy range where the quality of window detector transmission is reduced.

Moreover the Mass Absorption Coefficient (M.A.C.) of B-Ko in $\mathrm{Ni}$ is not well-known, as already mentioned by Bastin and Heijligers [17]. According to their literature review, $\mathrm{B}-\mathrm{K} \alpha$ in $\mathrm{Ni}$ is assumed to stand between $33,090 \mathrm{~cm}^{2} / \mathrm{g}$ and $41,500 \mathrm{~cm}^{2} / \mathrm{g}$. With our EPMA measurements and using StrataGem software, a MAC value of $41,500 \mathrm{~cm}^{2} / \mathrm{g}$ for B-K $\alpha$ in nickel was suitable to obtaining an FS parameter close to $100 \%$ on all the analyzed borides. This value corresponds to the highest value reported by Bastin and Heijligers for the absorption of $\mathrm{B}-\mathrm{K} \alpha$ in nickel. Similar analysis also showed that a variation of $10 \%$ of the MAC value (for example from 41,500 to $37,350 \mathrm{~cm}^{2} / \mathrm{g}$ ) reduced the Boron amount to 2 at.\% and increased the Ni/B ratio from 3.05 to 3.42. This highlights the influence of the MAC value on the Boron quantitation.

The choice of the standard is thus of great importance; unfortunately Ni-based superalloy standards containing a certified amount of Boron cannot be easily found. Should this be possible, then an empirical MAC value for $\mathrm{B}-\mathrm{K} \alpha$ in nickel could be directly obtained from electron probe microanalysis experiments carried out at various voltages using the XMAC software from Pouchou [18]. Unfortunately a commercial SEM/EDS/WDS software does not allow to modify the MAC value; in many cases the used value is unknown by the user.

Finally, it must be emphasized that in the B-K $\alpha$ energy range, numerous additional emitted peaks also do exist. Even with a high spectral resolution such as the one provided by WDS systems, a few peaks may still overlap. This is especially true for the Mo-M $\zeta$ and the $\mathrm{B}-\mathrm{K} \alpha$ emission lines (when analyzed by EDS). Thus the presence of Mo in the boride to be analyzed strongly increases the error associated with the Boron measurement.

For WDS systems, additional difficulties must been pointed out. First, the signal strongly depends on the analyzing crystal (here the LDE2H crystal was used for Boron). In addition, several cumbersome multi-order peaks could exist in the wavelength range of interest. As an example, $\mathrm{BN}$ is not a suitable standard for the analysis of Boron. Indeed, the 2 nd order $\mathrm{N}-\mathrm{K} \alpha$ peak lies very close to the $\mathrm{B}-\mathrm{K} \alpha$ peak and cannot be totally eliminated, even electronically using tight Pulse Height Analyzer windowing. Finally, like with other light elements, peak position (its centroid) and shape of the $\mathrm{B}-\mathrm{K} \alpha$ peak are sensitive to its chemical environment. Fig. 4 shows the B-K $\alpha$ peak of various Boron-containing standards, recorded by WDS. One can observe that the wavelength at the maximum of the peak shifts between $6.75 \mathrm{~nm}$ and $6.86 \mathrm{~nm}$. Also, we can notice subtle changes in the shape of the peak. Both effects illustrate the effect of chemical bonds for light elements [19]. Thus, a careful analysis of Boron requires either the same type of standard as the analyzed phase or an analysis of the global peak area (either directly or through the so-called Area-to-Peak factor [20]) and the possibility to subtract the adequate background part.

\subsection{Boron Quantitation: What is the Best Approach?}

Here, Boron was at first quantified on a boride of B-1 type (Cr, Mo,W-rich boride - Fig. 2a). Results obtained with three X-ray microanalysis techniques are presented in Table 3 (different standards were used for EDS analyses to evaluate their impact on the final results). Of course, precautions described earlier were also taken into consideration (see Section 3).

Our results show that an acceptable Boron level could be obtained by EDS when Boron was calculated using the difference method. Indeed, a Boron amount of 36 at.\% was found, compared to 34 at.\% using EPMA (our reference technique for Boron quantitation). This suggests that about $1 / 3$ rd of the atoms in this boride are Boron atoms. The error level can be estimated below 5 at.\%.

Table 3 - Composition (expressed as at.\%) of boride B-1 obtained using different techniques. The post-processing of the EDS and EDS/WDS spectra was done with $\phi(\rho z)$ method as available in the softwares. Boron was quantified either using the difference method or by measuring k-ratios (Eq. (1) with various standards $\left(10^{6}\right.$ counts for standard and spectrum). FS parameters before normalization are given in the last column.

\begin{tabular}{|c|c|c|c|c|c|c|c|c|c|c|c|c|}
\hline at. $\%$ & B & Al & $\mathrm{Si}$ & $\mathrm{Ti}$ & $\mathrm{Cr}$ & $\mathrm{Fe}$ & Co & $\mathrm{Ni}$ & Mo & $\mathrm{Ta}$ & W & FS wt. $\%$ \\
\hline Our reference: microprobe B standard & 34 & n.d. & n.d. & n.d. & 36.6 & 1.3 & 0.5 & 18.9 & 7.6 & n.d. & 1.1 & 100.4 \\
\hline EDS - B by difference & 36 & 0 & 0 & 0.1 & 34.5 & 1.3 & 0.5 & 17.8 & 8.2 & 0.2 & 1.4 & 100 \\
\hline EDS - B standard & 68 & 0.5 & 0 & 0 & 17.4 & 0.6 & 0.2 & 8.9 & 3.7 & 0 & 0.7 & 128.6 \\
\hline EDS - BN standard & 51 & 0 & 0 & 0 & 26.6 & 1.0 & 0.4 & 13.8 & 6.0 & 0.2 & 1 & 111.7 \\
\hline EDS - NiB standard & 13 & 0 & 0 & 0.1 & 47.2 & 1.8 & 0.6 & 24.4 & 11.0 & 0.1 & 1.8 & 94.6 \\
\hline EDS/WDS NiB standard & 48 & 0.4 & n.d. & n.d. & 28.7 & 1.0 & 0.4 & 14.3 & 6.35 & n.d. & 0.85 & 106.6 \\
\hline
\end{tabular}




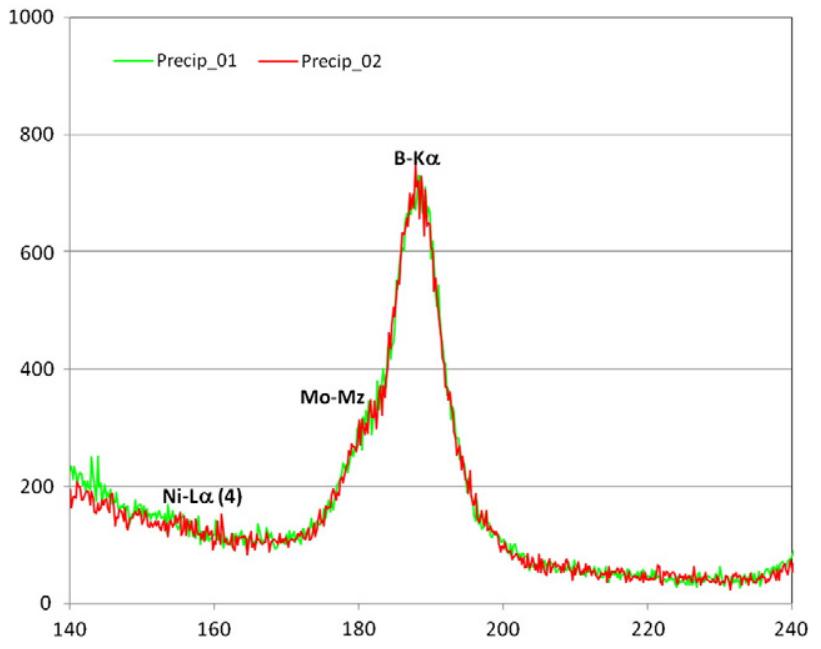

Fig. 5 - Spectra of ' $\mathrm{B}-1$ ' type borides recorded in the $0.30-0.15 \mathrm{keV}$ energy range using the JEOL JXA-8530F electron microprobe fitted with an LDE2H analyzing crystal. The $\mathrm{X}$-axis (in $\mathrm{mm}$ ) is linked to the position of the diffracting crystal in the equipment. Its scaling is proportional to wavelength. Since energy of the emitted photons is inversely proportional to wavelength, energy scale increases from right to left.

The EDS measurements using various standards gave significant discrepancies for the Boron content. The sum of elemental weight fraction FS was always significantly different from $100 \%$ whatever the applied standard. As a consequence, the normalized atomic \% of the main elements (here $\mathrm{Cr}, \mathrm{Ni}, \mathrm{Mo}$ ) were far from expectations. The low spectral resolution of an EDS system coupled with the signal weakness in the low energy range definitely excludes to measure Boron in such complex Ni-based matrix and thus whatever the applied standard sample.

SEM-WDS could then be an alternative by taking advantage of its improved spectral resolution compared to EDS. Unfortunately for this complex chemistry, the quantitation results were not better; the Boron level was evaluated to 48 at.\% with an FS parameter equal to $106 \%$. At that stage it might be worth recalling that the composition of this boride is the most difficult to determine due to the simultaneous presence of Mo and $\mathrm{B}$ (Fig. 5 depicts the Mo-M $\zeta$ and $\mathrm{B}-\mathrm{K} \alpha$ overlapping peaks as observed by EPMA). However the presence of Mo seems not to be the first order problem; Boron quantitation on the other types of borides gave similar discrepancies in Boron level compared to EPMA. The main problem for this chemistry is probably the limited options to process the data in the commercial software (better adjustment of background and working out data acquired at different accelerating voltages - as available on EPMA - would be required). Of course, the fact that it is impossible to have a certified standard with chemistry close to the borides counts also against a reliable result. However to the author's experience, SEM-WDS remains an interesting alternative for direct Boron quantitation in less complex chemistry [21].

This confirms that direct Boron quantitation in Ni-based matrix is not recommended with EDS or coupled EDS/WDS systems. The resulting error could lead to a misinterpretation of the nature of the boride and a wrong description of the mechanisms controlling the boride's formation during the brazing process.

\subsection{Boron Quantitation Results}

Thanks to the experience gained on boride B-1, borides B-2 and B-3 (Fig. 2) were analyzed independently using EPMA and SEMEDS. Measurements were performed exactly on the same borides to suppress the possibility of chemical variations intrinsic to the material. Table 4 summarizes the obtained results.

Here too, Boron could be measured by EDS using the difference method with an accuracy of about 3 to 5 at.\% (depending on the presence of molybdenum). However this precision degree could only be achieved once the levels for the other elements were precisely determined. Spectra containing at least $10^{6}$ counts are recommended for the standards and for the analyzed points. Ta-M $\alpha$ and W-M $\alpha$ emission lines should be used to measure Ta and $\mathrm{W}$ k-ratio.

From Table 4, it is also interesting to note that the larger discrepancies are observed for the major elements (Ni for the B-2 and B-3 borides and Cr for the B-1 borides). As expected, this correlates well with the error linked to the Boron

Table 4 - Composition (expressed as at.\%) of the three selected borides inside the brazed MC2 joint. In a few borides, the amount of $\mathrm{Al}, \mathrm{Si}$, Ti, and $\mathrm{Ta}$ was not determined by microprobe (n.d.) as the sum $\mathrm{Al}+\mathrm{Si}+\mathrm{Ti}+\mathrm{Ta}$ did not exceed $0.1 \%$. For each at.\%, an additional line indicates the atomic composition relative to a specific unit cell (this information is useful in to compare the elemental results with the crystal structures deduced by EBSD).

\begin{tabular}{|c|c|c|c|c|c|c|c|c|c|c|c|c|}
\hline & at.\% & B & $\mathrm{Al}$ & $\mathrm{Si}$ & $\mathrm{Ti}$ & $\mathrm{Cr}$ & $\mathrm{Fe}$ & Co & $\mathrm{Ni}$ & Mo & $\mathrm{Ta}$ & W \\
\hline \multirow[t]{4}{*}{ B-1 boride } & Microprobe at.\% & 34 & n.d. & n.d. & n.d. & 36.6 & 1.3 & 0.5 & 18.9 & 7.6 & n.d. & 1.1 \\
\hline & Unit cell\% (10 atoms) & 3.4 & & & & 3.7 & 0.1 & 0.0 & 1.9 & 0.8 & & 0.1 \\
\hline & EDS at.\% & 36 & 0 & 0 & 0.1 & 34.5 & 1.3 & 0.5 & 17.8 & 8.2 & 0.2 & 1.4 \\
\hline & Unit cell\% (10 atoms) & 3.6 & 0.0 & 0.0 & 0.0 & 3.5 & 0.1 & 0.0 & 1.8 & 0.8 & 0.0 & 0.1 \\
\hline \multirow[t]{4}{*}{ B-2 boride } & Microprobe at.\% & 20 & 1.8 & 0.5 & 1.2 & 3.0 & 1 & 0.5 & 70.5 & 0.1 & 1.2 & 0.1 \\
\hline & Unit cell\% (29 atoms) & 5.8 & 0.5 & 0.1 & 0.3 & 0.9 & 0.3 & 0.1 & 20.5 & 0.0 & 0.3 & 0.0 \\
\hline & EDS at.\% & 18 & 1.9 & 1.3 & 1.2 & 3.1 & 1. & 0.7 & 72 & 0.1 & 0.7 & 0.2 \\
\hline & Unit cell\% (29 atoms) & 5.2 & 0.5 & 0.4 & 0.3 & 0.9 & 0.3 & 0.2 & 20.8 & 0.0 & 0.2 & 0.1 \\
\hline \multirow[t]{4}{*}{ B-3 boride } & Microprobe at.\% & 24 & 0 & 0.1 & 0 & 2.5 & 0.7 & 0.5 & 72.3 & 0.1 & 0 & 0 \\
\hline & Unit cell\% (4 atoms) & 1. & 0.0 & 0.0 & 0.0 & 0.1 & 0.0 & 0.0 & 2.9 & 0.0 & 0.0 & 0.0 \\
\hline & EDS at. $\%$ & 21 & 0.1 & 0.2 & 0 & 2.7 & 0.7 & 0.5 & 74.4 & 0.1 & 0 & 0.1 \\
\hline & Unit cell\% (4 atoms) & 0.9 & 0.0 & 0.0 & 0.0 & 0.1 & 0.0 & 0.0 & 3.0 & 0.0 & 0.0 & 0.0 \\
\hline
\end{tabular}


Table 5 - Composition (expressed as at.\%) of B-2 and B-3 borides. More than 15 points were measured per boride type.

\begin{tabular}{llcccccccrrrr} 
& \multicolumn{1}{c}{ at.\% } & $\mathrm{B}$ & $\mathrm{Al}$ & $\mathrm{Si}$ & $\mathrm{Ti}$ & $\mathrm{Cr}$ & $\mathrm{Fe}$ & $\mathrm{Co}$ & $\mathrm{Ni}$ & $\mathrm{Mo}$ & $\mathrm{Ta}$ & $\mathrm{W}$ \\
\hline \multirow{2}{*}{ B-2 boride } & Average composition & 18 & 1.7 & 1.2 & 1.0 & 3.9 & 1.2 & 0.4 & 71.4 & 0.1 & 0.8 & 0.2 \\
& Standard deviation & 3.0 & 0.2 & 0.3 & 0.2 & 0.3 & 0.1 & 0.1 & 2.8 & 0.1 & 0.1 & 0.1 \\
B-3 boride & Average composition & 25 & 0.1 & 0.1 & 0 & 3.1 & 0.8 & 0.4 & 70.3 & 0.1 & 0.1 & 0.1 \\
& Standard deviation & 2.8 & 0.1 & 0.1 & 0.1 & 0.5 & 0.2 & 0.1 & 2.5 & 0.1 & 0.1 & 0.1 \\
\hline
\end{tabular}

measurement. As a result, a careful recording of the main element standard is mandatory in order to minimize errors linked to the quantitation of this element.

Finally, the measurements on B-2 and B-3 borides have been repeated to evaluate their chemical homogeneity as well as the reproducibility of the quantitation process (only few B-1 types Cr,Mo,W-rich borides were found and no statistics could be run).

The result in Table 5 shows that the variation measured from one location to the next is of the same order than the discrepancy between the two techniques (about 3 at.\%). Interestingly, a clear correlation was found between $\mathrm{B}$ and $\mathrm{Ni}$ levels (as displayed in Fig. 6), underlying again the importance of a careful quantitation of the main element. This correlation suggests that the dispersion is mainly due to the uncertainty in the quantitation method rather than a real chemical heterogeneity of the borides.

Despite the high accuracy of the composition reached with optimized EDS technique or EPMA, it remains difficult to identify exactly the type of borides. Indeed, a large variety of borides of type ( $M B, M_{3} B, M_{3} B_{2}, M_{23} B_{6}$ ) are possible in Ni-based superalloys brazed with filler metal containing $\mathrm{B}$ and/or $\mathrm{Si}$ $[1,6,7]$. Numerous Cr-rich borides do also exist with close Boron levels. For instance $\mathrm{Cr}_{5} \mathrm{~B}_{3}$ leads to a theoretical Boron level of 37.5 at.\%, whereas $\mathrm{Cr}_{3} \mathrm{Mo}_{3} \mathrm{~B}_{4}$ leads to a Boron level of 40 at.\%.

The difference in Boron level can well be within the range of the experimental error of the microanalysis measurements. Thus, in the next section, the possibility of using EBSD coupled with EDS was explored to obtain additional information for boride identification, taking crystallographic features into account.

\section{Contribution of Coupled EBSD/EDS Techniques for the Identification of Borides}

In this section, it is shown that coupled EBSD/EDS measurements enable the crystal structure of the 3 selected borides

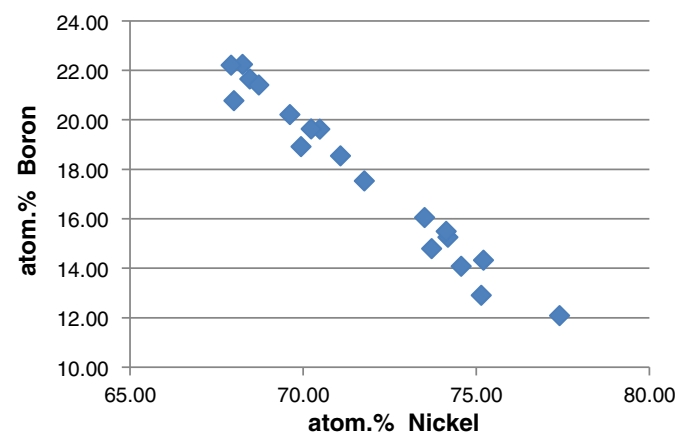

Fig. 6 - Experimentally measured amount of Boron vs. measured amount of $\mathrm{Ni}$ in 'B-2' type borides (i.e., containing $\mathrm{Ni}$, Ti \& $\mathrm{Ta}$ ) using EDS analysis.
(B-1, B-2 and B-3 in Fig. 2a) to be identified unambiguously. Their Kikuchi patterns could be indexed successfully with the advanced interactive phase identification mode available in the software tool box (as summarized in Fig. 7).

Borides of B-3 type were the easiest to analyze. They had diffraction patterns of $\mathrm{Ni}_{3} \mathrm{~B}$ crystal structure (space group no. $62-$ crystal symmetry Pnma). Each Kikuchi pattern measured on these borides had 12 diffraction bands in common with a theoretical pattern of $\mathrm{Ni}_{3} \mathrm{~B}$ phase (see an example in Fig. 7a, b). Moreover $\mathrm{Ni}_{3} \mathrm{~B}$ was clearly the only phase in the large ICSD database offering this high number of band matching between experimental and simulated patterns (and consistent with the qualitative chemistry proposed by the EDS/EBSD system prior to phase identification). A comparison between experimental (Fig. 7a) and simulated patterns (Fig. 7b) confirms that both are fully consistent.

The $\mathrm{Ni}_{3} \mathrm{~B}$ stoichiometry obtained by EBSD is also fully consistent with the one deduced from microanalysis measurements (in the range of Ni2.9 $0.1 \mathrm{~B} 1$ (microprobe) and Ni3 $\times 0.1$ B0.9 (EDS) - see Table 4).

Borides of B-2 type had diffraction patterns of a $\mathrm{Ni}_{23} \mathrm{~B}_{6}$ crystal structure (space group 225 - crystal symmetry Fm-3 m) (see an example in Fig. 7c, d). Here too, $\mathrm{Ni}_{23} \mathrm{~B}_{6}$ was clearly the only phase in the large ICSD database offering 12 common bands between the experimental and simulated patterns.

It must be noticed that this phase could be easily misindexed as a Ni-rich phase from the same space group (number 225). Indeed, the diffraction patterns of both phases share a high number of band positions. However, subtle intensity differences are present.

In the EBSD software, the intensities associated to the different reflectors are evaluated by kinematic simulation. The reflector list produced for the $\mathrm{Ni}_{23} \mathrm{~B}_{6}$ and $\mathrm{Ni}$ phases is slightly different in intensities of multi-order reflectors (due to the difference in atomic composition of the cell). Moreover \{311\} reflectors present with a high intensity for Ni-based phase have a too low intensity to be detected for $\mathrm{Ni}_{23} \mathrm{~B}_{6}$. Thus EBSD allows to discriminate both phases providing that a high number of experimental bands is detected and used to find the best solution.

Here too, the $\mathrm{Ni}_{23} \mathrm{~B}_{6}$ stoichiometry obtained by EBSD is fully consistent with the one deduced from microanalysis measurements (in the range of Ni20.5 × 2.7 B5.8 (microprobe) and Ni20.8 $\times 3$ B5.2 (EDS) - Table 4). However this precise stoichiometry could not be directly and solely deduced from the microanalysis results. Indeed, other compounds like $(\mathrm{NiX})_{3}$ or ${ }_{4} \mathrm{~B}$ fit also with the elemental analysis, taking into account the limited precision of the microanalysis techniques (5 at.\%). This demonstrates the valuable contribution of EBSD to boride's identification.

Finally, the borides of B-1 type are chromium rich. They exhibit the diffraction pattern of a crystal structure belonging 
a)

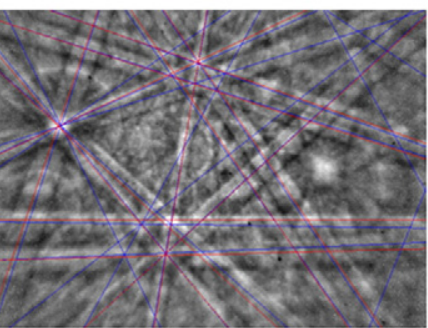

b)

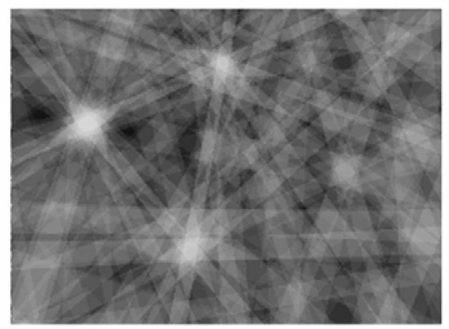

Boride B-3:

$\mathrm{Ni}_{3} \mathrm{~B}$ (4 atoms)

Space group $\mathrm{N}^{\circ} 62$
C)

Experimental Kikuchi Patterns

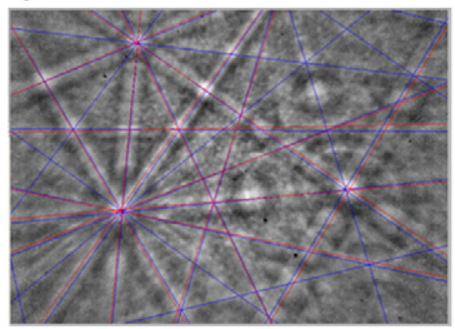

d)

Simulated Kikuchi Patterns

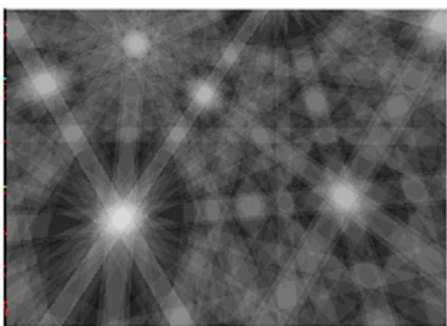

Boride B-2:

$\mathrm{M}_{23} \mathrm{~B}_{6}$ (29 atoms)

Space group $N^{\circ} 225$ e)

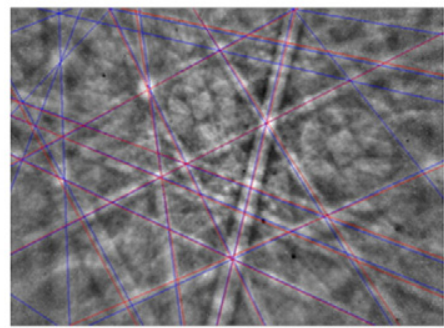

f)

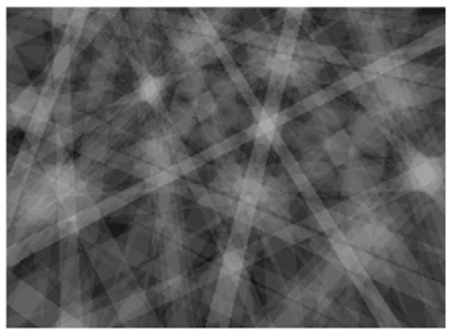

Boride B-1:

$\mathrm{B}_{4} \mathrm{Mo}_{2.16} \mathrm{Ti}_{1.278} \mathrm{Cr}_{1.278}$

$\mathrm{Fe}_{0.864} \mathrm{Ni}_{0.42}$ (10 atoms)

Space group $\mathrm{N}^{\circ} 127$

Fig. 7 - Crystal structure identification of various borides using coupled EBSD/EDS analysis. Columns are respectively associated to 'B-3', 'B-2' and 'B-1'-type borides. Images of the experimentally-obtained \& calculated Kikuchi Electron Backscatter Diffraction patterns of selected borides are presented; along with the corresponding crystal structures (at the bottom).

to the space group no. 127 - crystal symmetry $\mathrm{P} 4 / \mathrm{mbm}$ (see an example in Fig. 7e, f). They are typical of a complex chromium iron molybdenum nickel titanium boride with the following composition proposed in the ICSD database (Ni0.42 Mo2.16 Ti1.278 Cr1.278 Fe0.864 B4). Again, this was the only phase in the database that exhibited 12 common bands between the experimental and simulated patterns. Other chromium rich borides like $\mathrm{Cr}_{5} \mathrm{~B}_{3}$ or $\mathrm{Cr}_{3} \mathrm{~B}_{4}$ often found in brazed Ni-based superalloys are definitely to be excluded. ${ }^{1}$

In that case, the phase identified by EBSD has no chemistry determined by quantitative microanalysis (Ni1.9 Mo0.8 Ti0 Cr3.7 Fe0.1 W0.1 B3.4 - Table 4). No Ti was observed and the Cr, Mo and $\mathrm{Ni}$ contents were significantly different. However the measured ratio between Boron and the other metallic elements $(\times 6.6$ B3.4) was not too far from the ( $\times 6$ B4) suggested by EBSD.

Once all the phases were identified, EBSD technique was used in the mapping mode (with a step size of $0.2 \mu \mathrm{m}$ ) to identify how these phases were distributed over a part of the region imaged in Fig. 1. The map was acquired with a speed of 100 points/s. With such high acquisition speed, the EDS signal that was acquired simultaneously could only provide limited (qualitative) information about the elemental distribution of the elements. The result is shown in Fig. 8. The 3 boride's crystal structures and the Ni-based structure were used to index the Kikuchi patterns.

\footnotetext{
${ }^{1} \mathrm{Cr}_{5} \mathrm{~B}_{3}$ : space group no. 140 - crystal symmetry $\mathrm{I} / \mathrm{mmm}$ and $\mathrm{Cr}_{3} \mathrm{~B}_{4}$ : space group no. 71 - crystal symmetry Immm.
}

Only one chromium boride (B-1 type) could be found in the analyzed region. It was depicted with a dark blue color in Fig. $8 \mathrm{~b}$ and was successfully indexed. Additional mapping in other regions has confirmed that only few of these chromium borides were present in the microstructure.

$\mathrm{M}_{23} \mathrm{~B}_{6}$ borides ( $\mathrm{B}-2$ type) were not only found in the solidification front but also close to the interface between the base metal and the joint. This suggests that they precipitate at the early stage of the isothermal solidification process. Some of them actually grow within the Ni-based solidification front (see for example the wide boride of B-2 type in Fig. 2a). The small-sized borides at the interface were well identified. This identification takes advantage of the high spatial resolution offered by EBSD in comparison to EDS.

$\mathrm{Ni}_{3} \mathrm{~B}$ borides (B-3 type) (light blue on the map) had a low indexation percentage due to the weak contrast of the Kikuchi patterns. However, the results are good enough to ensure reliable identification of this phase. Improved surface preparation could possibly increase the fraction of indexed pixels over this phase.

The rest of the material was indexed as Ni-based phase (in red). This includes the base metal, the solidification front, and finally the eutectic region. However, comparing the EBSD map and the EDS map, one can notice important chemical variations. In particular, Si as diffusing element present in the filler metal was mostly concentrated in the eutectic zone (Fig. 8c).

This deep characterization of the brazed MC2 joint definitely demonstrates that the different modes to 

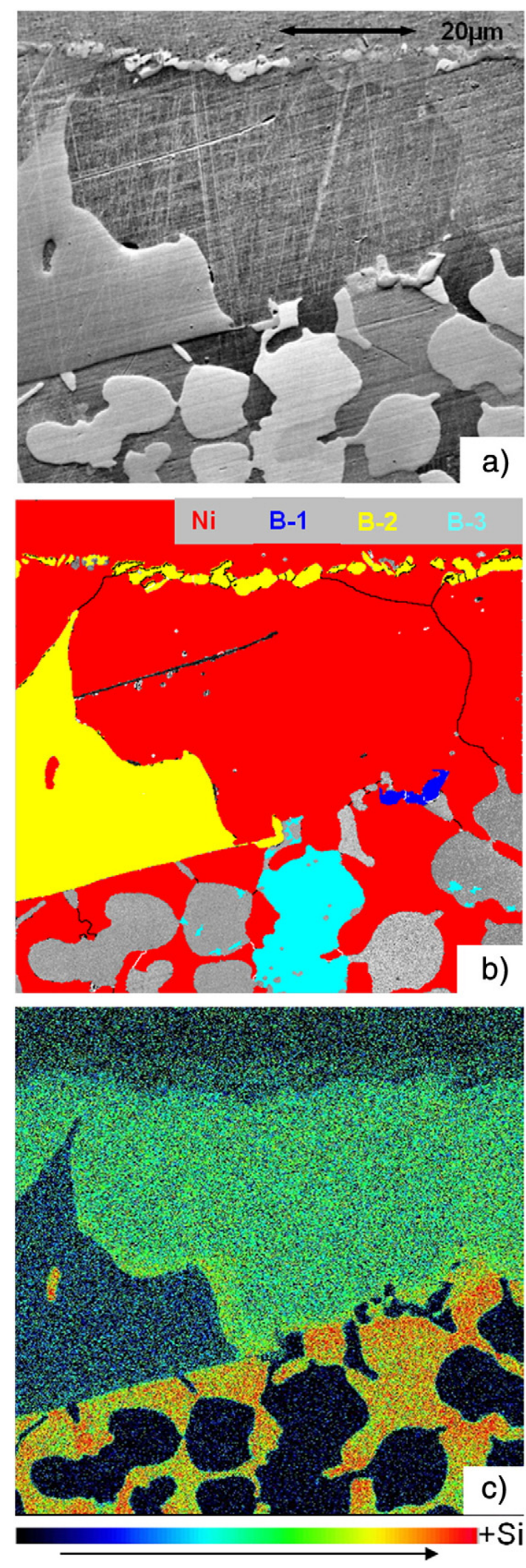

Fig. 8 - EBSD and EDS elemental mapping images of the brazing area described in Fig. 2a. (a) Image with the forward scatter detector. (b) EBSD phase map. (c) Si-K $\alpha$ EDS mapping after peak deconvolution (the color indicates the qualitative variations in Si content). combine EBSD/EDS really provide rich information for accurate boride's identification. All the process can reasonably be run with a speed of 100 points/s and with a resolution in a range of a few tens of nanometers. Thus compared to EDS analysis alone, the overall speed of the data collection is increased as well as the spatial resolution of the final characterization.

\section{Conclusions}

In this contribution the different phases formed in a brazed MC2 Ni-based superalloy have been studied to evaluate how precise the state-of-the-art microanalysis systems attached to a SEM (EDS, WDS, EBSD) could quantify Boron and provide an accurate identification of the boride types.

Our main conclusion is that the best method to quantify Boron using EDS is definitely by composition difference. Indeed, the multi-elements of a $\mathrm{Ni}$ based superalloy can be quantified with a precision of about 0.5 at.\% for each element. Consequently the Boron level can reasonably be determined by difference and an overall precision of 5 at.\% can be obtained. To reach this precision, the classical recommendations for high resolution EDS must be applied as detailed in the present paper.

All attempts for direct Boron quantitation with EDS or coupled EDS/WDS systems using different standards gave less accurate results. The measurement error can easily lead to a misinterpretation of the boride nature and a wrong description of the mechanisms controlling the boride's formation during the brazing process.

Despite this improved Boron quantitation, couples of borides with low Boron stoichiometry variations still get mixed up after EDS analysis.

Our second conclusion is that EBSD coupled with EDS can differentiate these different borides by collecting qualitative chemical information simultaneously with crystallographic information. This advanced phase identification mode consists in using the chemical information to pre-filter the crystallographic phase candidates from a database and further indexation of the EBSD diffraction patterns enables a conclusive identification of the boride.

Once all phases have been identified, EBSD maps can be acquired to analyze the spatial distribution of the detected phases over a large area. Simultaneous EDS signal acquisition serves for qualitative mapping of the elemental distribution.

Our analyses definitely demonstrate that these two modes to combine EBSD and EDS really improve the richness of information available to characterize a brazed Ni-based superalloy. Compared to EDS analysis alone, the overall speed of the data collection is increased as well as the accuracy and the spatial resolution of the final characterization.

\section{Acknowledgments}

The authors are grateful to D. Galy from SYNERGIE4 for fruitful discussions to optimize EDS measurements. They also thank Daniel P. Turner for having the brazed samples done at Pratt \& Whitney Canada. 


\section{R E F E R E N C E S}

[1] Piegert S. Modern high temperature brazing processes for turbine blade and vane repair. $\mathrm{PhD}$ thesis Fakultät für Maschinenbau, Technischen Universität Carolo-Wilhelmina; 2011.

[2] Ruiz-Vargas J, Siredey-Schwaller N, Bocher P, Hazotte A. First melting stages during isothermal brazing of $\mathrm{Ni} / \mathrm{BNi}-2$ couples. J Mater Process Technol 2013;213:2074-80.

[3] Gale WF, Wallach E. Influence of isothermal solidification on microstructural development in Ni-Si-B filler metals. Mater Sci Technol 1991;7:1143-7.

[4] Kim D, Nishimoto K. Bonding. Phenomena of transient liquid phase bonded joints of a Ni base single crystal superalloy. Met Mater Int 2002;8(4):403-10.

[5] Yuan X, Kang CY, Kim MB. Microstructure and XRD analysis of brazing joint for duplex stainless steel using a Ni-Si-B filler metal. Mater Charact 2009;60:923-31.

[6] Abdelfatah M, Ojo O. On the extension of processing time with increase in temperature during transient-liquid phase bonding. Metall Mater Trans A 2009;40:377-85.

[7] Egbewande AT, Chukwukaeme C, Ojo OA. Joining of superalloy Inconel 600 by diffusion induced isothermal solidification of a liquated insert metal. Mater Charact 2008;59:1051-8.

[8] Ohsasa K, Shinmura T, Narita T. Numerical modeling of the transient liquid phase bonding process of $\mathrm{Ni}$ using $\mathrm{Ni}-\mathrm{B}-\mathrm{Cr}$ ternary filler metal. J Phase Equilib 1999;20(3):199-206.

[9] Arafin MA, Medraj M, Turner DP, Bocher P. Transient liquid phase bonding of Inconel 718 and Inconel 625 with BNi-2: modeling and experimental investigations. Mater Sci Eng A 2007;447:125-33.

[10] Ritchie NWM, Newbury DE, Davis JM. EDS measurements of $\mathrm{X}$-ray intensity at WDS precision and accuracy using a silicon drift detector. Microsc Microanal 2012;18(4):892-904.
[11] Maniguet L, Robaut F, Meuris A, Roussel-Dherbey F, Charlot F. $\mathrm{X}$-ray microanalysis: the state of the art of SDD detectors and WDS systems on scanning electron microscopes (SEM). IOP conference series. Mater Sci Eng 2012;32:1-18.

[12] Simonetti M, Caron P. Role and behaviour of $\mu$ phase during deformation of a nickel-based single crystal superalloy. Mater Sci Eng 1998;A254:1-12.

[13] Pouchou JL. In: Brisset F, editor. Microscopie électronique à balayage et microanalyses. GN-MEBA Publ., EDP Sciences; 2008. p. 435-70 [chapter XII].

[14] Holton I. Is energy-dispersive spectroscopy in the SEM a substitute for electron probe microanalysis? Microsc Anal 2012;26(4):S4-7 [compositional Analysis supplement].

[15] Schwartz Adam J, Kumar Mukul, Adams Brent L, Field David $\mathrm{P}$, editors. Electron backscatter diffraction in materials science. 2nd ed. Springer; 2010 [chapter 1 (1-20) and chapter 6 (p. 81-95)].

[16] Nowell MM, Wright SI. Phase differentiation via combined EBSD and XEDS. J Microsc 2004;213:296-305.

[17] Bastin GF, Heijligers. Quantitative electron probe microanalysis of boron. J Solid State Chem 2000;154:177-87.

[18] Pouchou JL. Use of soft X-rays in microanalysis. Mikrochim Acta 1996;13:39-60 [Suppl.].

[19] Ruste J. In: Brisset F, editor. Microscopie électronique à balayage et microanalyses. EDP Sciences; 2008. p. 471-82 [chapter XIIa].

[20] Bastin GF, Heijligers HJ. Quantitative electron probe microanalysis of carbon in binary carbides. I Principles and procedures. X-Ray Spectrom 1986;15(2):135-41.

[21] Portebois L, Mathieu S, Bouizi Y, Vilasi M, Mathieu S. Effect of boron addition on the oxidation resistance of silicide protective coatings: a focus on boron location in as-coated and oxidised coated niobium alloys. Surf Coat Technol 2014 (in press). 